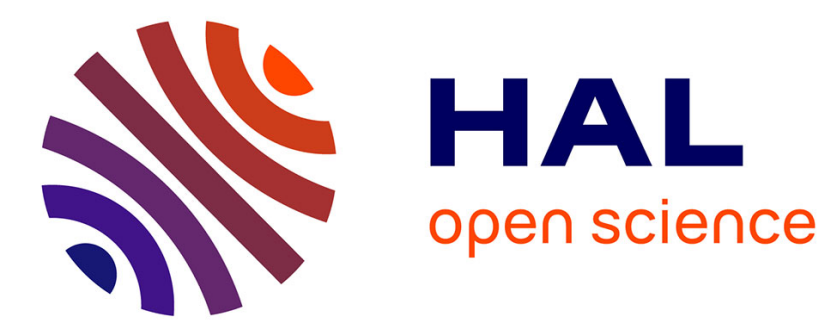

\title{
Quartz Crystal Resonator Used as an Optical Fabry-Perot Cavity
}

Kevin Rosenziveig, Jérémy Bon, Philippe Abbé, Valérie Soumann, Nicolas Passilly, Serge Galliou, Pierre Cohadon

\section{- To cite this version:}

Kevin Rosenziveig, Jérémy Bon, Philippe Abbé, Valérie Soumann, Nicolas Passilly, et al.. Quartz Crystal Resonator Used as an Optical Fabry-Perot Cavity. International Frequency Control Symposium and European Frequency and Time Forum, Apr 2019, Orlando, United States. hal-02472687

\section{HAL Id: hal-02472687 \\ https://hal.science/hal-02472687}

Submitted on 10 Feb 2020

HAL is a multi-disciplinary open access archive for the deposit and dissemination of scientific research documents, whether they are published or not. The documents may come from teaching and research institutions in France or abroad, or from public or private research centers.
L'archive ouverte pluridisciplinaire HAL, est destinée au dépôt et à la diffusion de documents scientifiques de niveau recherche, publiés ou non, émanant des établissements d'enseignement et de recherche français ou étrangers, des laboratoires publics ou privés. 


\section{Quartz Crystal Resonator Used as an Optical Fabry-Perot Cavity}

Kevin Rosenziveig, Jérémy Bon, Philippe Abbé, Valérie Soumann, Nicolas Passilly, Serge Galliou FEMTO-ST, Univ. Bourgogne Franche-Comté, CNRS ENSMM 25030 Besançon, France contact: kevin.rosenziveig@femto-st.fr

\begin{abstract}
The best plano-convex quartz crystals resonators can have quality factors up to a few billion at low temperature, which makes them interesting for ultrastable clocks. For this application, it's best they are optomechanically actuated. The first step towards this is to demonstrate they can be used as optical FabryPerot cavities with almost no change to their typical piezoelectric building. This paper is focused on the feasability of such optical use.
\end{abstract}

Keywords-Optics, Quartz Resonator, Fabry-Perot, Optical Cavity, Acoustic Cavity, Optomechanics

\section{Introduction, BACKGROUND}

Quartz crystals are used in time standards routinely. Moreover, the quality of synthetic materials have been improved up to the point where the product $Q \times f$ gets to $10^{13}$ for the best ones at room temperature.

Furthermore, such quartz resonators (QR) in the cryogenic $4 \mathrm{~K}$ region can have quality factors $(Q)$ as high as a few billion [1].

Earlier studies [2] have shown that the flicker frequency level of the power spectral density of the fractional frequency fluctuations behaves as $S_{y}(1 \mathrm{~Hz}) \propto \frac{1}{Q^{a}}$ with $a \approx 4$. Very good performances can therefore be achieved, with possible fractional frequency deviation floor, or Allan deviation floor, as low as $10^{-16}$.

All these considerations qualify cryo-cooled quartz as a candidate for ultra-stable clock. We need to implement some vibration control and a way to impede performancelimiting frequency instabilities due to temperature fluctuations. The latter problem has been solved[3] by the finding of a specific compensated cut for the quartz crystal in this temperature region.

To be able to actuate the quartz crystal, piezoelectricity is usually called upon. In our setup however, this would bring further noise to account for, because of variable temperature fluctuations at different stages of the solid link between the oscillation sustaining system (at room temperature) and the QR which sits on the cold finger of the cryorefrigirator.

MENESR France for K.R. research scholarship

Région Franche-Comté and Labex First-TF for their funding dedicated to this program

Oscillator IMP platform (Equipex) for reference frequencies

\author{
Pierre-François Cohadon \\ Laboratoire Kastler Brossel, \\ UPMC-Sorbonne Universités, CNRS, \\ ENS-PSL Research University, Collège de France, \\ 75005, Paris, France
}

A way to circumvent this is to actuate the quartz optically instead. Indeed, if we are able to use the radiation pressure, we can avoid thermal dilation fluctations in the excitation link. Because the radiation pressure is very weak, we use the fact that the two electrodes used for actuating the quartz piezoelectrically also are two mirrors "glued" together with the QR. By sending a laser on these, we can use the radiation pressure of the hence amplified light intensity inside the cavity to create vibrations of our QR. For this, we should modulate the laser intensity at the acoustic frequency[4]. We will first demonstrate the feasability of using such QR as Fabry-Perot cavities.

\section{Quartz Crystal as a Fabry-Perot Cavity}

Typical QR manufactured for frequency references here at FEMTO-ST are plano-convex crystal cavities, with a thickness of few $\mathrm{mm}$ with a thin layer (around 5-15 nm) of Chromium on the quartz on top of which a much larger layer of Gold (around $200 \mathrm{~nm}$ ) is deposited. The reason for the Chromium layer is that it sticks well to the quartz, whereas the Gold does not. Gold, in turn, sticks well onto the Chromium layer.

The particular QRs we use are plano-convex $1 \mathrm{~mm}$ thick lenses, with a radius of curvature of $250 \mathrm{~mm}$. Figure 1 shows such a metallized QR which does not seem of surface quality incompatible with our uses. In these conditions, the $g$ stability factor for a Fabry-Perot cavity is $g=0.996$, very close to 1 when instability for optical cavities starts[5].

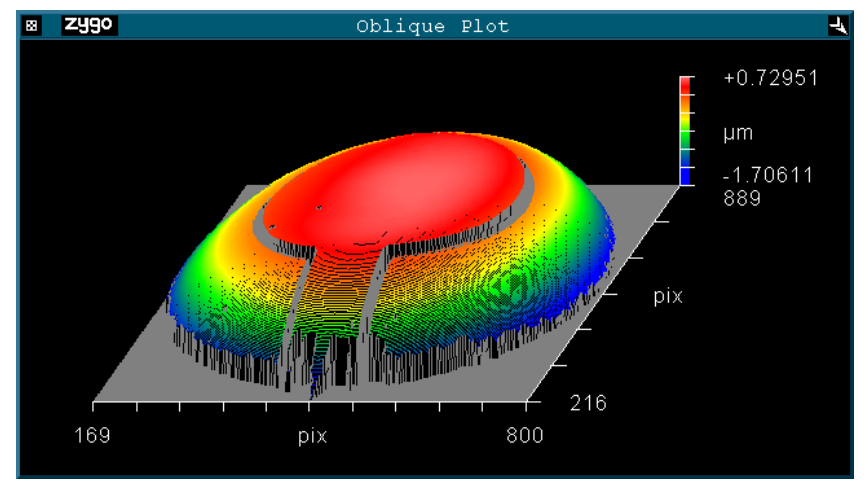

Fig. 1. Surface of one of our metallized Quartz Resonator 


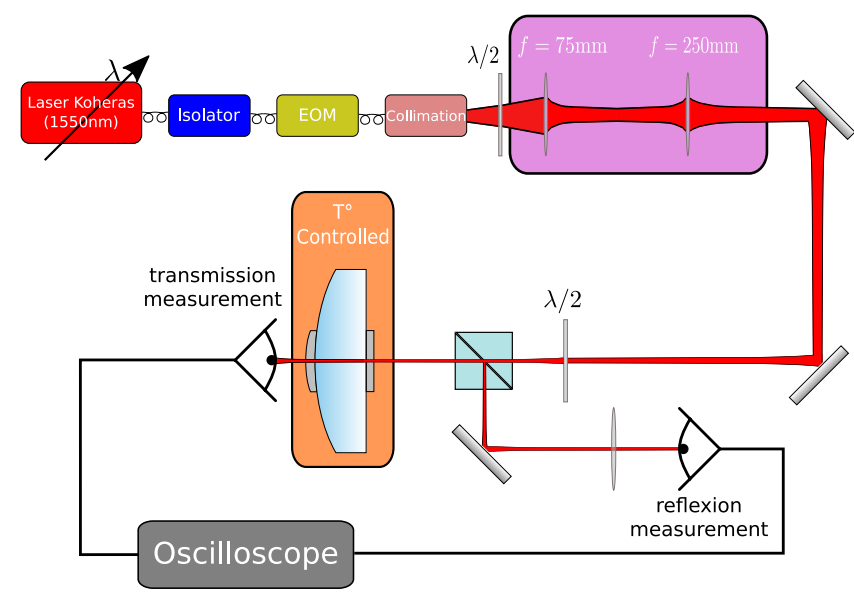

Fig. 2. Our experimental setup

Gold, in the infrared region, is reflective to about $98 \%$ [6] for $\approx 100 \mathrm{~nm}$ layers. It is generally considered[6] that films more than $\approx 200 \mathrm{~nm}$ are certain to behave just like their bulk counterpart whereas quantum effects need to be taken into accout for films thinner than $20 \mathrm{~nm}$.

All these considerations lead us to believe that a common metallized QR could be used in a straightforward manner as an optical Fabry-Perot cavity. From these, we expect a finesse $F=\frac{\pi \sqrt{R}}{1-R}$ with $R$ the intensity reflection coefficient of the whole Fabry-Perot cavity. In our case, the Finesse should amount to about $F=155$. Furthermore, the typical Fabry-Perot cavity gives a transmission maximum and a reflection minimum for the resonance condition $\lambda=\frac{2 L}{m}$ with $m \in N^{*}$.

\section{EXPERIMENT, RESUlts}

In our experimental setup, the laser, optical isolator and EOM are all fibered as seen in figure 2 . We have put a $\frac{\lambda}{2}$ plate before the beam splitter to be able to compensate for the birefringence of the $\mathrm{QR}$, and align the polarization of our beam to one of the QR's fast or slow axes.

Because of the quartz having an index of refraction $n_{\text {quartz }} \approx 1.54$, the wavelength inside is modified with respect to that of vacuum. This phenomenon accounted for, the mode-matching demands that we have a waist of $71 \mu \mathrm{m}$ at the (entrance) plane side, so that the beam's radius of curvature matches that of the end mirror.

Our first results with Chromium-Gold coated QR were discouraging, and it was found that Chromium was a poor candidate for making a mirror[7]. It is indeed the Chromium that the light inside the quartz first "sees". Eliminating altogether the Chromium layer was investigated, but did not turn out well, as a "blistering"[8] effect on the gold was observed.

This lead us to use Silver instead, whose intensity reflection coefficient is comparable to that of Gold at our wavelengths, and whose main defect with respect to gold is that it gets oxydated whereas gold does not. On the other
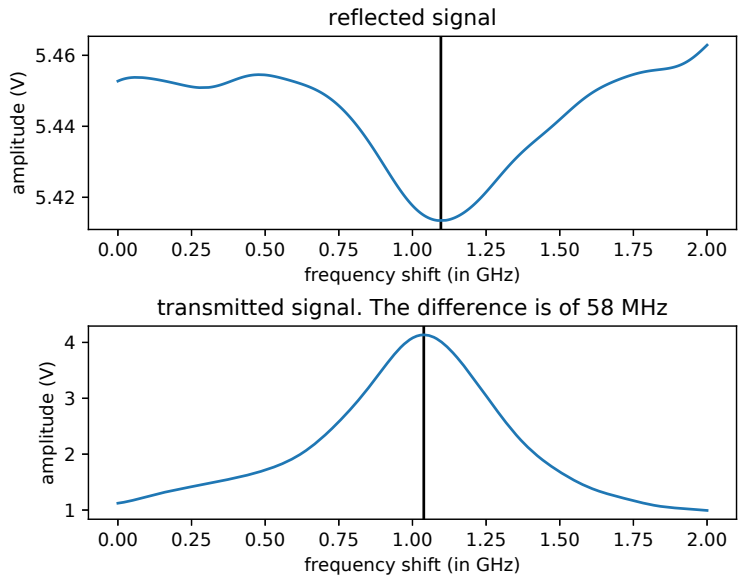

Fig. 3. Transmission and reflection for a $60-60 \mathrm{~nm}$ Ag metallized QR (noise filtered data).

hand, Silver sticks better to the quart and the "blistering" effect does not seem to happen as much.

The results obtained for a $60-60 \mathrm{~nm}$ Silver metallized QR were surprising, as there was a frequency shift between the extrema of the transmitted and the reflected peaks. As it turns out, this is in fact a known phenomenon[9] and it is due to the absorption of the mirrors. The measured difference between the peaks is $58 \mathrm{MHz}$ and the theoretical value is $37.5 \mathrm{MHz}$

Contrary to the typical case, the theoretical extrema of transmission and reflection are limited. In our case, the transmission and reflection maxima are theoretically limited to $T=4 \%$ and $\frac{R_{\min }}{R_{\max }}=12 \%$. We measure, however, a reflection visibility of $\approx 3 \%$ and a transmission of $\approx 3 \cdot 10^{-4}$.

\section{Conclusions}

The common QR can be used as a Fabry-Perot cavity, by adapting the metallization. Investigation is under progress to better understand the discrepencies between the theoretical and experimental values. A systematic investigation of the bandwidths for the transmission and reflection peaks will be lead.

\section{ACKNOWLEDGMENT}

K.R. would like to thank R. Giust, J. Millo and C. Lacroûte for the fruitful discussions.

\section{REFERENCES}

[1] S. Galliou, P. Abbe, R. Bourquin, M. Goryachev, M. E. Tobar, and E. N. Ivanov, "Properties related to Qfactors and noise of quartz resonator-based systems at $4 \mathrm{k}, "$ in 2014 European Frequency and Time Forum (EFTF). Neuchatel, Switzerland: IEEE, Jun. 2014, pp. 3335. [Online]. Available: http://ieeexplore.ieee.org/lpdocs/epic03/ wrapper.htm?arnumber $=7331419$ 
[2] J.-J. Gagnepain, J. Uebersfeld, G. Goujon, and P. Handel, "Relation between $1 / \mathrm{f}$ noise and Q-factor in quartz resonators at room and low temperatures, first theoretical interpretation," Proceeding 35th annual Frequency Control Symposium, pp. 476480, May 1981.

[3] J. Bon, R. Bourquin, J.-J. Boy, and S. Galliou, "Frequency-Temperature Compensated Cuts of Crystalline-Quartz Acoustic Cavity Within the Cryogenic Range [4 K, $15 \mathrm{~K}]$," IEEE Transactions on Ultrasonics, Ferroelectrics, and Frequency Control, vol. 65, no. 9, pp. 1738-1740, Sep. 2018. [Online]. Available: https://ieeexplore.ieee.org/document/8384306/

[4] J. Bon, L. Neuhaus, S. Deléglise, T. Briant, P. Abbé, P.-F. Cohadon, and S. Galliou, "Cryogenic optomechanic cavity in low mechanical loss material," Journal of Applied Physics, vol. 124, no. 7, p. 073104, Aug. 2018. [Online]. Available: http://aip.scitation.org/doi/10.1063/1.5042058

[5] H. Kogelnik and T. Li, "Laser Beams and Resonators," Applied Optics, vol. 5, no. 10, p. 18, Oct. 1966. [Online]. Available: https: //www.osapublishing.org/ao/abstract.cfm?uri=ao-5-10-1550

[6] D. I. Yakubovsky, A. V. Arsenin, Y. V. Stebunov, D. Y. Fedyanin, and V. S. Volkov, "Optical constants and structural properties of thin gold films," Optics Express, vol. 25, no. 21, p. 25574, Oct. 2017. [Online]. Available: https: //www.osapublishing.org/abstract.cfm?URI=oe-25-21-25574

[7] A. D. Rakić, A. B. Djurišić, J. M. Elazar, and M. L. Majewski, "Optical properties of metallic films for verticalcavity optoelectronic devices," Applied Optics, vol. 37, no. 22, p. 5271, Aug. 1998. [Online]. Available: https://www.osapublishing. org/abstract.cfm?URI=ao-37-22-5271

[8] N. B. Dahmane, G. Parry, and R. Estevez, "Cloquage de films minces ductiles sur substrat rigide," in CFM 2015, Lyon, 2015, p. 4. [Online]. Available: https://www.researchgate.net/publication/290130608 Cloquage de films minces ductiles sur substrat rigide

[9] J. J. Monzón and L. L. Sánchez-Soto, "On the concept of absorption for a Fabry-Perot interferometer," American Journal of Physics, vol. 64, no. 2, pp. 156-163, Feb. 1996. [Online]. Available: http://aapt.scitation.org/doi/10.1119/1.18135 